\title{
A GENERAL METHOD OF TOUGHENING GOLD (AND SILVER) IN THE MELTING CRUCIBLE.
}

By Dr. James C. Booth, of the U. S. Mint, Philadelphia.

Gold and silver differ from other elements, except those of the platinum group in their feeble affinity for oxygen, and by means of this property, we can separate the noble metals from others by fusion in the fire, in which heat removes oxygen from gold and silver and attaches it to the others. To this first class we may add a second, embracing iron, nickel, copper, tin, bismuth, and lead, whose oxides may be reduced to metal by being heated with fuel, or without reduction can be melted with fluxes or slag. A third class, arsenic, antimony and sulphur, are reduced and volatilized, or are fluxed off with alkali and oxides of the second class.

To illustrate the subject practically, I shall describe an operation of toughening brittle gold, which I recently performed at the United States Mint at Philadelphia. Some brittle gold, having been accidently melted with a quantity of well refined and tough gold, was found to have rendered the whole mass very brittle, with a highly crystalline fracture, and therefore useless for coinage. I determined to avoid loss of time, and the greater cost of refining by acid, and to toughen it wholly by fluxing. This was accomplished on $75,162 \frac{56}{100}$ ounces $(=5,154$ lbs. av. $)$ in $1 \frac{1}{2}$ days, at a trifling cost, and with scarcely apparent loss. The 75,000 oz. were divided into 14 melts of about 5,400 oz. each, and each melt separately toughened. The ingots, easily broken into pieces by striking them on the edge of a wooden box, were put into the crucible with soda ash and anhydrous, fused borax, in the ratio of one or two ounces to a melt, until the crucible was nearly full. It then appeared as a quiet mass of metal covered with a rather viscid slag, disposed to swell and puff. A few crystals of saltpetre, say one or two ounces, were then dropped successively into the centre of the metallic surface, and as they melted, their spreading out over the whole surface was aided by the concentric motion of the bottom of a small crucible. The moment the visible oxidizing action began to slacken, the melter skimmed off, by a small, blacklead dipping crucible, the fluxed matter as rapidly as was consistent with the care necessary to avoid taking up metal. The remainder in the melting pot was the toughened metal. 
There are several points worth noting in the operations just decribed. 1. One part of the foreign matter was sufficient to impart brittleness to 75,000 parts of good standard gold (st. gold $=900$ gold $\perp 100$ copper, \&c.). 2. By a slight oxidizing process the matter causing brittleness was collected and removed at a trifling cost in $1 \frac{1}{2}$ days, without appreciable loss of goll. 3. Still more remarkable is the fact that the 14 melts of gold, in their brittle state, proved by assay to be of true standard, 900 gold -100 alloy (usually 90 copper +10 silver), after their brittleness had been changed to toughness by fluxing and skimming, were still 9100 gold +100 alloy, inappreciably altered. So delicately executed is the act of toughening, that although 10 per cent. of the metal is easily oxidized copper, yet the ratio of copper after fluxing is the same. 4. Another point worthy of remark is that the toughening proceeds from the top downward, to the depth of 9 to 12 inches of its own accord, although it is stirred towards the close of the operation to render the melt uniform throughout.

I do not wish the inference to be drawn that every case of toughening brittle gold is as successful or simple as the above. When the metal contains a larger proportion of foreign matter, the operation of fluxing, nitring and skimming may have to be repeated, perhaps more than once. While the crucible is on the fire, the perfection of the toughening may be readily ascertained in 2 or 3 minutes by casting a thin strp, $-\frac{3}{4}$ inch thick, and doubling it under the hammer or rolling it, the cracking of the strip in this case, if any, or its snapping asunder, informing the experienced eye of the degree of completeness in the toughening operation.

When the bullion appears to be baser-to contain a larger amount of foreign matter than in the example specially quoted in this paper, and experience can of ten make an approximate guess at the degree of baseness as well as at the nature of the elements causing it, then the only change made in the toughening consists in using a larger amount of soda and borax, and a still larger proportion of nitre. Two points are to be noted in the use of a large amount of this more oxidizing flux: 1 . That some of the graphite of the crucible at the level of the liquid is cut away, injuring the cruucible and weakening the oxidizing power of the nitre. 2. That since the larger bulk of fluxing matter increases, the time of skimming, some of the oxidized foreign matter, in the presence of a 
large amount of metal, and surrounded by graphite, tends to revert to the metallic state.

To obviate these difficulties or objectionable features, after going through the stronger oxidizing process, as above described, the oxidation is suddenly fixed by the rapid addition to the floating slag of sand lime or bone ash, which is stirred with the slag and thickens or stiffens it, so as to allow more deliberate skimming of the whole mass without fear of reoridization. I bave tried the three thickeners above named, which seem to act rather mechanically than chemically, and, of the three, prefer sand. Where thickeners are employed on standard gold, there is greater liability to an increase in fineness of the standard by the removal of oxide of copper, together with the oxidized embrittler, so that brittle gold of 900 after toughening may be 900.5 or even 901 .

The toughening of the above $75,000 \mathrm{oz}$. effected in 14 meltinge (14 crucibles full) of over $5,000 \mathrm{oz}$. each in standard gold, resulted in less than a crucible full of skimmings. The skimmings are worked down to metal and poor slag as follows. They are quietly melted and cooled slowly, so as to form a king of metal at the bottom of the crucible, and a glassy or cindery slag above. The last is ground and separated by sifting and washing into metallic grains and poor cinder. The grain and king are again fluxed and treated as before, either by themselves, or as usual with other light residues. Thus, the impurities of gold (and silver) are successively worked out, by concentrating them in a small hulk and weight of metal, and purifying it with a greater diminished risk of loss of gold than if we attempted to purify a large mass at one operation. In the case detailed in this paper, the impurities were concentrated by a single operation of purifying in a king of about (8) eight oz. From the purification of this king, we have ground for asserting that the impurity causing brittleness in the whole $75,000 \mathrm{oz}$. was a small fraction of an ounce, probably $\frac{1}{300,000}$ or less, of the original weight.

As a concluding note to this paper, I must state that a great deal of skill is required to avoid loss of gold in executing the process herein detailed; that the melter must have unusual powers of observation and long practice to acquire the necessary skill, and I deem it but justice to state that Mr. F. C. Garrigues, my foreman, especially in the melting department of the Mint, possessess the requisite skill and practice, and that he performed the operations above described. 